\title{
Acid and Base Catalysed Transesterification of Mango (Mangifera Indica) Seed Oil to Biodiesel.
}

\author{
Ogunsuyi H.O \\ Department of Chemistry, Federal University of Technology, Akure P.M.B. 704, Akure Ondo State, Nigeria
}

\begin{abstract}
Biodiesel production from Mango (mangifera indica) seed oil using acid and base catalysed transesterification method has not been documented, however, the physicochemical properties of the oil has been extensively studied. In order to establish optimum condition for the production of biodiesel from the seedoil, parameters such as catalyst concentration, reaction temperature, agitation speed and oil to methanol ratio were varied. However, direct base catalyzed transesterification produced no biodiesel due to the high Free Fatty Acid (FFA) value of the oil. Hence, acid pretreatment was preferred prior to base transesterification which afforded a significant reduction of the FFA value from $3.3 \%$ to $0.9 \%$ and a biodiesel yield of $88 \%$.

Keywords: Biodiesel, Extraction, Mangifera Indica,, Pretreatment, Transesterification
\end{abstract}

\section{Introduction}

The major part of all energy consumed in most parts of the world comes from fossil sources such as petroleum, coal and natural gas. However, these non-renewable sources will be exhausted in near future. Recent assessments of remaining petroleum reserves show the world will soon face a relentless oil-supply crisis. Within the next fifteen years, worldwide production of conventional crude oil is projected to peak and decline irreversibly. Alternative sources for petroleum products will then be critical. [1-2]

If the nation's source of petroleum products continues to be limited to conventional crude oil, this situation is certain to become worse. Widely acknowledged estimates of remaining recoverable reserves of conventional crude oil worldwide total 1 trillion barrels. Thus, the search for alternative sources of renewable and sustainable energy has gained importance with the potential to solve many current social issues such as the rising price of petroleum crude and environmental concerns like air pollution and global warming caused by combustion of fossil fuels [3-4]. The term biofuel or renewable fuel is referred to as solid, liquid or gaseous fuels that are predominantly produced from biomass. Liquid and gaseous biofuels have become more attractive recently because of its environmental benefits. Biofuels are non-polluting, locally available, accessible, sustainable and reliable fuel obtained from renewable sources [5-6]. Among other reasons why biofuels are considered as relevant technologies by both developing and industrialized countries are: energy security, environmental concerns, foreign exchange savings, and socio-economic issues related to the rural sectors of all countries in the world [7]. In recent years, many studies have investigated the economic and environmental impacts of biofuels, especially bioethanol, biodiesel, biogas, and biohydrogen [6]. Biodiesel (fatty-acid alkyl esters) is a renewable and environmentally friendly energy source. It can be produced from plant oils and animal fats. Several techniques are available for biodiesel production. The most commonly used technique is transesterification in which triglycerides are reacted with alcohol, usually methanol, in the presence of a catalyst, usually potassium or sodium hydroxide $(\mathrm{KOH}$ or $\mathrm{NaOH})$, to produce mono alkyl esters. Many factors affect the biodiesel yield and process economics. The most important factors are alcohol type, alcohol/oil molar ratio, reaction temperature and time, catalyst type and amount and water content of the reactants [8]. Mangos belong to the genus Mangifera of the family Anacardiaceae. The genus Mangifera contains several species that bear edible fruit. Most of the fruit trees that are commonly known as mangos belong to the species Mangifera indica. The other edible Mangifera species generally have lower quality fruit and are commonly referred to as wild mangos. Mango fruit is classed as a drupe (fleshy with a single seed enclosed in a leathery endocarp). Fruits from different varieties can be highly variable in shape, color, taste and flesh texture. Fruit shapes vary from round to ovate to oblong and long with variable lateral compression. Fruits can weigh from less than $50 \mathrm{~g}$ $(0.35 \mathrm{lb})$ to over $2 \mathrm{~kg}(4.4 \mathrm{lb})$. The fruit has a dark green background color when developing on the tree that turns lighter green to yellow as it ripens [9]. Currently, Nigerian government has shown great interest in Jatropha and other biofuel plants. The aim of the government is to gradually reduce the nation's dependency on gasoline, reduce environmental pollutions as well as create commercially viable industry that can precipitate domestic job [10-11].

Hence this study aimed at quantifying the percentage oil yield and biodiesel output of the oil of Mango (mangifera indica) seed grown in Ondo State, Nigeria as this is a major waste during its season after the fleshy back has been taking as food. Controlling the waste generated from mango, converting the oil extracted from the seed to biodiesel and the seed cake if properly treated as raw materials for producing livestock feeds. 


\section{1: Materials}

\section{Materials and methods}

All reagents were of analytical grades and gotten from the Department of Chemistry Federal University of Technology Akure, Nigeria

\section{2: Sample Collection.}

The mango (Mangifera Indica) fruits were collected from five different farmyard remains along Ilesha - Akure express way and the University Staff Quarters of the Federal University of Technology Akure during the mango fruiting season in Nigeria. The fleshy tenacious part of the fruit was removed leaving the seed, which was sun- dried for 5 days afterwards dehulled. The dehulled seeds were cut into smaller chunks, blended, dried, transferred into an extraction vessel and soaked with n- hexane (B.P. $40-60^{\circ} \mathrm{C}$ ) for 3 days. The extraction process was repeated 3 times for proper extraction [11]. The extracted oil-solvent mixture was refluxed in a soxhlet extractor until the oil was adequately recovered.

\section{3: Physico-chemical properties of the extracted oil}

The physico-chemical analysis of the oil involved the determination of iodine value (AOAC, 1975), free fatty acid (FFA) (AOAC, 1995), acid value (AOAC, 1995), Saponification Value (AOAC, 1975; Pearson, 1976), pH value (Pearson, 1981), smoke point (AOAC, 1990), fire point (AOAC, 1990), refractive index (AOAC, 1990) and specific gravity (AOAC, 1975).

\section{4: Acid pretreatment process.}

The pretreatment was conducted in a corked $250 \mathrm{ml}$ flat bottom flask, placed on a hot plate magnetic stirrer preset at the required temperature. In the experiments, flasks loaded with Mangifera indica oil samples was first heated to the designated temperature of $50^{\circ} \mathrm{C}[17]$ This was followed by the addition of the methanol and sulfuric acid (The solution of concentrated $\mathrm{H}_{2} \mathrm{SO}_{4}$ acid $1.0 \%$ based on the weight of oil, and the oil to methanol ratio of $1: 6$ by volume and a reaction time of $70 \mathrm{~min}$ ). The Transesterification pretreated products oil was separated in a tap funnel to obtain the upper layer, which was then washed with water several times until the $\mathrm{pH}$ of the washing water was close to 7.0. The resultant pretreated oil was dried in an oven before the subsequent transesterification process [18]

\section{5: Experimental conditions}

Experiments were planned to ascertain the oil/methanol ratio (w/w), catalyst concentration, reaction temperature and agitation intensity on transesterification reaction. The ratio of Oil/Methanol was varied as per $\mathrm{w} / \mathrm{w} 4: 1,5: 1,6: 1$, the catalysts was sodium hydroxide and its concentrations were varied as $0.25,0.50,0.75$, 1.00 and $1.50 \%$ of the oil. Reaction temperatures considered were 50, 55, 60 and $65^{\circ} \mathrm{C}$ and the agitation intensity were varied through 150, 300, 450, 600 and $700 \mathrm{rpm}$.

\section{6: Transesterification}

Base catalyzed transesterification was carried out according to the Ireland method 1. In a $250 \mathrm{ml}$ conical flask equipped with a magnetic stirrer. $30 \mathrm{ml}$ of the extracted oil was taken in flask and potassium hydroxide (1 percent of oil's weight) dissolved in methanol (22.5 percent of oil's weight) was added to flask. Stirring was continued for $90 \mathrm{mins}$ at $60^{\circ} \mathrm{C}$, the mixture was transferred to a separatory funnel and glycerol was allowed to separate, leaving the upper layer biodiesel and the lower layer glycerin [19-20]

\section{7: Biodiesel separation and washing}

After obtaining the biodiesel phase, methyl ester was washed with hot water three times until the residual catalyst is finally off the solution. Warm water at temperature of about $50^{\circ} \mathrm{C}$, usually ratio $1: 1$ to the biodiesel was used in each washing step to clean up the esters. Finally, the biodiesel was dried in an oven at 105 degree for 30mins.

\section{8: Fuel properties}

The following properties of the biodiesel produced were determined: density and specific gravity [11], kinematic viscosity $40^{\circ} \mathrm{C}$ (ASTM D 445), flash point (ASTM D 93), Sulfated Ash (ASTM D847) carbon residue (ASTM D524).

\section{Results and discussion}

\subsection{Physico-chemical properties of the oil of Mangifera Indica.}

The percentage oil yield and the physico-chemical properties of the extracted oil were determined. After the extraction it was found out that the seed contains $14.7 \%$ of oil, which was slightly higher than $14.0 \%$ reported by Nzikou et al [21]. The variation in the oil yield could be attributed to the extracting solvent, 
Acid And Base Catalysed Transesterification Of Mango (Mangifera Indica) Seed Oil To Biodiesel. differences in variety of plant, cultivation climate. In this study $n$ - hexane was used as against petroleum ether that was employed by Nzikou et al, [21]. From the result in Table 1, the iodine value was observed to be slightly higher than 32.0 reported by Bligh \& Dyer method and lower than that of Soxhlet method in the same report [21]. The FFA value of the seed -oil, was slightly lower compared with that reported by Nzikou et al.[21]

\section{2: Pretreatment of the Extracted oil}

If the percentage of FFA is over 2.5 wt. \% direct base catalyzed transesterification is not advised to eliminate excess soap formation. Pretreatment is necessary to reduce the content of FFA before base catalyzed transesterification step [22]. The acid pretreatment process reduced the FFA value by $72.73 \%$ from $3.3 \mathrm{mg} / \mathrm{g}$ to $0.9 \mathrm{mg} / \mathrm{g}$.

Table 1: Physico-Chemical Parameters of Mangifera Indica Seed Oil.

\begin{tabular}{|l|l|}
\hline PARAMETER & MEAN \pm S.D \\
$\mathrm{pH}$ & $3.75 \pm 0.12$ \\
\hline Iodine Value $(\mathrm{mg} / \mathrm{g})$ & $32.99 \pm 0.12$ \\
\hline Free fatty acid, FFA(mg/g) & $3.30 \pm 0.13$ \\
\hline Acid Value $(\mathrm{mg} \mathrm{KOH} / \mathrm{g})$ & $6.60 \pm 0.26$ \\
\hline Saponification Value $(\mathrm{mg} / \mathrm{g})$ & $210.38 \pm 1.32$ \\
\hline Unsaponifiable matter $(\%)$ & $2.07 \pm 0.47$ \\
\hline Smoke point $\left.{ }^{0} \mathrm{C}\right)$ & $128.00 \pm 1.63$ \\
\hline Flash point $\left({ }^{\circ} \mathrm{C}\right)$ & $242.00 \pm 1.24$ \\
\hline Refractive Index & $1.47 \pm 000$ \\
\hline Specific Gravity & $0.89 \pm 0.04$ \\
\hline
\end{tabular}

Values are mean \pm S.D of triplicate determination

\section{3: Effects of Catalyst}

From Fig. 1, it was seen that the yield of biodiesel from the pretreated oil of Mangifera Indica oil was highest at catalyst concentration of $0.5 \%$ weight of oil, and thereafter at higher catalyst concentration $0.75 \%$ and $1.0 \%$, the yield decreased with the formation of emulsion of higher viscosity. It was found out that there was no feasible yield of biodiesel at catalyst concentration of $1.5 \%$.

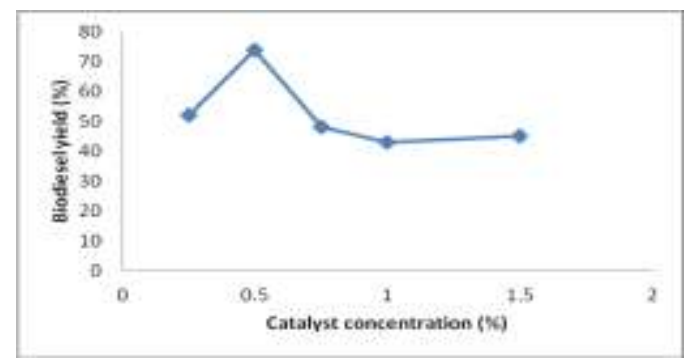

Fig 1: plot of catalyst concentration against yield of biodiesel

\section{4: Effect of Reaction Temperature}

The result of various reaction temperatures could be seen in Fig. 2. The reaction temperature was varied from $50^{\circ} \mathrm{C}$ to $65^{\circ} \mathrm{C}$ at an interval of $5^{\circ} \mathrm{C}$. It was observed that the yield of biodiesel from the pretreated oil of mangifera indica increased from temp. $50^{\circ} \mathrm{C}$ and was highest at temp. $60^{\circ} \mathrm{C}$ and thereafter at higher temperature the yield decreased. This reduction in the yield of biodiesel could be due to the excessive evaporation of methanol at higher temperature and the boiling point of methanol used was found to be $63.4^{0} \mathrm{C}$.

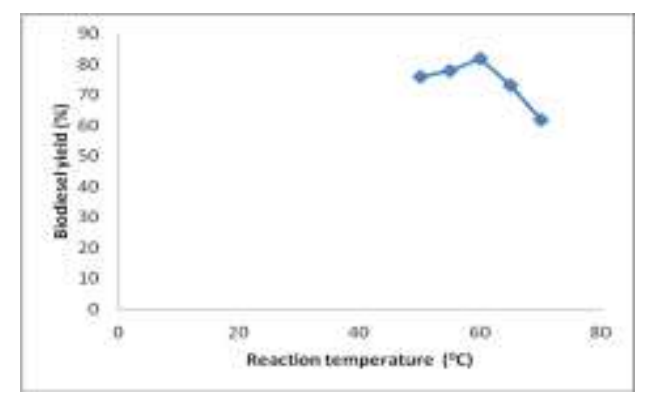

Fig 2: plot of reaction temperature against yield of biodiesel. 
Acid And Base Catalysed Transesterification Of Mango (Mangifera Indica) Seed Oil To Biodiesel.

\section{5: Effect of agitation intensity}

The effect of agitation speed on the reacting mixture is important to ensure proper mixing of the reactant to ensure completion of the conversion process. The percentage yield of biodiesel from the oil of mangifera indica oil increases as the agitation speed increases up to 600 and decreased afterward above this speed as can be seen in fig 3 .

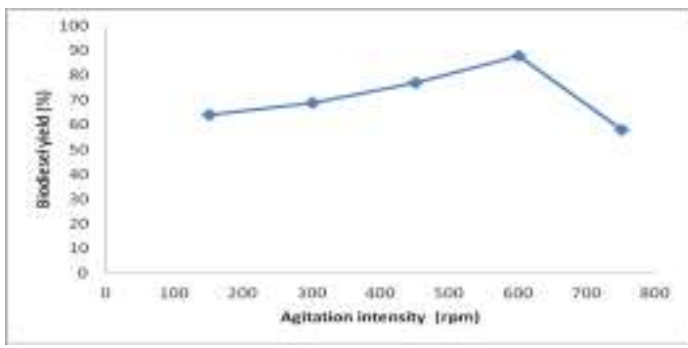

Fig 3: plot of agitation intensity against yield of biodiesel.

\section{5: Transesterification}

In the transesterification of mangifera indica seed oil using the direct base catalyzed transesterification [20]. It was observed that direct base catalyzed transesterification did not take place in the heated oil of mangifera indica oil, taking all reaction conditions into consideration instead the fat solidifies on cooling. It was deduced that this was caused by the high FFA value of $3.3 \mathrm{mg} / \mathrm{g}$ and according to Joon et al.[23] who reported that any source of oil that has significant amount of FFA $(>1 \%)$ would not be fully converted into biodiesel because those FFAs would undergo saponification and lead to soap formation [24]. After the pretreatment process, the FFA value was reduced from 3.3 to $0.9 \mathrm{mg} / \mathrm{g}$ then, the base catalyzed transesterification produced biodiesel taken reaction conditions such as: catalyst concentration of 0.5 weight percent of the total weight of the reactant, temperature of $60^{\circ} \mathrm{C}$ and agitation speed of 600 rpm into consideration.

\section{6: Biodiesel washing and separation.}

The separated biodiesel recovered was light yellow in color with a sweet smell and the washed out waste water which contains excess Methanol soap and the glycerin was a cloudy milk color solution.

\section{7: Fuel properties}

The physicochemical properties of biodiesel from mangifera indica oil were considered and the result is as shown in Table 2. To ascertain the potential of the derived- biodiesel as a substitute to petroleum diesel fuel, the following parameters such as density, specific gravity, kinematic viscosity, sulfated ash, and flash point were determined.

The density of the biodiesel was found to be consistent with the values reported by Umer et al [25] and Haq et al.[20] Also, the specific gravity of the biodiesel compared favorably with those reported by Adebayo et al. and Belewu et al.[11,26]. Flash point which is a measure of the tendency of a sample to form flammable mixtures with air and also an important parameter for the safe handling and storage of fuel was found to be above the standard minimium value as depicted in Table 2, this implies that the mangifera indica biodiesel is potentially safe for both storage and handling. In addition, the flash point reported conforms well to the finding of Aldo et al, who reported transesterification of castor oil for biodiesel. The ash content of the derivedbiodiesel is quite consistent with that documented in Adebayo et al, [11] however, comparatively higher than that specified in the standard in Table 2. Generally, the data gotten from the methyl ester of mangifera indica mostly consistent with those of the standard as shown in Table 2.

Table 2: Physico-Chemical Parameters of Biodiesel from Mangifera Indica oil.

\begin{tabular}{|l|l|l|l|}
\hline Parameters & $\begin{array}{l}\text { Mangifera indica } \\
\text { biodiesel }\end{array}$ & $\begin{array}{c}\text { USA } \\
\text { ASTM D 6751 }\end{array}$ & $\begin{array}{l}\text { EU } \\
\text { EN 14214 }\end{array}$ \\
\hline Specific Gravity & 0.870 & NM & NM \\
\hline Density & 0.873 & $\mathbf{0 . 8 8 0}$ & $\mathbf{0 . 8 8 0}$ \\
\hline Flash Point ${ }^{\mathbf{0}} \mathbf{C}$ & $178^{0} \mathrm{C}$ & $\mathbf{1 3 0 . 0}$ min & $\mathbf{1 2 0}$ min \\
\hline Kinematic Viscosity & 4.3 cts & $\mathbf{1 . 9 - 6 . 0}$ & $\mathbf{2 . 5 - 5 . 0}$ \\
\hline Sulphated Ash & 0.040 & $\mathbf{0 . 0 2 0}$ max & $\mathbf{0 . 0 2 0}$ \\
\hline pH value & 6.23 & NM & NM \\
\hline Acid Value( mgKOH/g) & 0.78 & $\mathbf{0 . 5 0}$ max & $\mathbf{0 . 5 0}$ max \\
\hline FFA (mg/g) & 0.59 & NM & NM \\
\hline Refractive Index & 1.42 & NM & NM \\
\hline
\end{tabular}


Acid And Base Catalysed Transesterification Of Mango (Mangifera Indica) Seed Oil To Biodiesel.

Key: Min (minimum)
Max (maximum)
NM (not mentioned in ASTM standard)

\section{Conclusion}

Biodiesel derived from pretreated oil of mangifera indica is suitable for use as fuel as the kinematic viscosity and flash point conform to standard. Although, some parameters like the sulphated ash and acid value are little higher than the their specified standard values. Therefore, biodiesel production from the oil of mangifera indica seed oil should be encouraged not only for creating treasure from trash but also serves as a means of relieving the environment of the discarded seeds of the fruit during the harvest season.

\section{Acknowledgement.}

The contributions of Messrs Abass Lukman Taiwo and Sodiya James are gratefully acknowledged.

\section{References}

[1] Campbell, C.J.: "Depletion Patterns Show Change Due for Production of Conventional Oil," Oil \& Gas Journal, December 29, 1997.

[2] Laherrere, J.H.: "World Oil Supply--What goes up must come down, but when will it peak?," Oil \& Gas Journal, February 1, 1999.

[3] May Ying Koh, Tinia Idaty Mohd. Ghazi, A review of biodiesel production from Jatropha curcas L. oil. Renewable and Sustainable Energy Reviews 15 (2011) 2240-2251.

[4] Demirbas A. Biodiesel production from vegetable oils via catalytic and non-catalytic supercritical methanol transesterification methods. Progress in Energy and Combustion Science 2005; 31:466-87.

[5] Demirbas A. Biofuels securing the planet's future energy needs. Energy Conversion and Management 2009; 50:2239-49.

[6] Fatih M. Demirbas, Mustafa Balat, Havva Balat. Biowastes-to-biofuels. Energy Conversion and Management 52 (2011) 18151828

[7] Demirbas A, Dincer K. Sustainable green diesel: a futuristic view. Energy Sources A 2008; 30:1233-41.

[8] Meher L C, Vidya Sagar D, Naik S N. Technical aspects of biodiesel production by transesterification: a review. Renewable and Sustainable Energy Reviews, (2006) 10(3), 248-268.

[9] Bally, I.S.E. 2006. Mangifera indica (mango), ver. 3.1. In: Elevitch, C.R. (ed.). Species Profiles for Pacific Island Agroforestry. Permanent Agriculture Resources (PAR), Hōlualoa, Hawai'i. <http://www.traditionaltree.org $>$.

[10] Federal Government of Nigeria Policy on Biofuel, 2008. Federal Republic of Nigeria official Gazette on Nigeria Biofuel policy and Incentives Fellows P. 1997.

[11] Adebayo G.B, Ameen O.M and Abass L.T. Physico-chemical properties of biodiesel produced from Jatropha Curcas oil and fossil diesel. J. Microbiol. Biotech. Res., 2011, 1 (1): 12-16.

AOAC, (1975) Official Method of Analysis (11 $1^{\text {th }}$ edition), Washington DC.

[13] AOAC, (1990) Official Method of Analysis (14 ${ }^{\text {th }}$ edition), Washington DC.

[14] Pearson, D., (1976). Chemical Analysis of Food. $7^{\text {th }}$ Edition, Church Hill Livingstone, UK. pp: 488-496.

[15] Pearson, D., (1981). Chemical Analysis of Food. $8^{\text {th }}$ Edition, Church Hill Livingstone, UK. pp: 507-545.

[16] AOAC, (1995) Official Method of Analysis (15 $5^{\text {th }}$ edition), Washington DC.

[17] Hanny Johanes Berchmans, Shizuko Hirata. Biodiesel production from crude Jatropha curcas L. seed oil with a high content of free fatty acids. Bioresource Technology 99 (2008) 1716-1721

[18] Houfang Lu, Yingying Liu, Hui Zhou, Ying Yang, Mingyan Chen, Bin Liang. Production of biodiesel from Jatropha curcas L. oil. Computers and Chemical Engineering 33 (2009) 1091-1096.

[19] Rice B., Frohlich A., Leonard R., Teagasc, Korbitz W. Bio-Diesel Production Based on Waste Cooking Oil: Promotion of the Establishment of An Industry in Ireland, Altener Contract No. XVII/4.1030/AL/77/95/IRL. Final Report (1997).

[20] Haq Nawaz Bhatti, Muhammad Asif Hanif, Umar Faruq, Munir Ahmad Sheikh. Acid and Base Catalyzed Transesterification of Animal Fats to Biodiesel. Iran. J. Chem. Chem. Eng. Vol. 27, No. 4, 2008. Pg. 41-48.

[21] Nzikou J.M, A. Kimbonguila, L. Matos, B. Loumouamou, N.P.G. Pambou-Tobi, C.B. Ndangui, A. A. Abena, Th. Silou, J. Scher and S. Desobry. Extraction and Characteristics of Seed Kernel Oil from Mango (Mangifera indica). Research Journal of Environmental and Earth Sciences 2(1): 31-35, 2010.

[22] Dennis Y.C. Leung, Xuan Wu, M.K.H. Leung. A review on biodiesel production using catalyzed transesterification. Applied Energy 87 (2010) 1083-1095

[23] Joon Ching Juan, Damayani Agung Kartika, Ta Yeong Wub, Taufiq-Yap Yun Hin. Biodiesel production from jatropha oil by catalytic and non-catalytic approaches: An overview. Bioresource Technology 102 (2011) 452-460.

[24] Aldo Okullo, A.K. Temu, P. Ogwole, J.W. Intalikwa. Physico- chemical properties of Biodiesel from Jatroph and Castrol Oils. International Journal of renewable Energy Research. Vol. 2, No.1, 2012.

[25] Umer Rashid, Farooq Anwar, Gerhard Knothe. Evaluation of biodiesel obtained from cotton seed Oil. Fuel Processing Technology 90 (2009) 1157-1163).

[26] M.A Belewu, F.A Adekola, G.B. Adebayo, O.M Ameen, N.O. Mohammed. A.M. Olaniyan, O.F Adekola and A.K. Musa. Physico- chemical charateristics of Oil and Biodiesel from Nigerian and Indian Jatropha curcs Seed. International J.Biolo. Chem. Sci. 4 (2): 524-529, April 2010 